\title{
Users and their use of information*
}

\author{
An Informal Discussion on 20 Year Trends in Scientific Scholarly Journal Readership Patterns: \\ Implications for Electronic Journal System Participants
}

Diane Hoffman

Hoffman Information Services

Chair:

Eugene Garfield, President Elect of ASIS

Garfield introduces three leading researchers in the field of scholarly communications for an informal conversation on the results of their findings on scholarly communications and user behavior with emphasis on the implications and application for NFAIS services.

Speakers:

Donald King

Jose-Marie Griffiths

Carol Tenopir

\begin{abstract}
Author and Lecturer
University Chief Information Officer and Executive Director, Information Technology Division, University of Michigan

Professor, University of Tennessee

20 Years Trends in Scientific Scholarly Journal Readership Patterns: Implications for Electronic Journal System Participants.
\end{abstract}

\section{Users \& Their Use of Information}

This session is structured as an informal discussion between the panel and the audience about what we know about scientists as users of scholarly materials and how this information can be applied to the new digital initiatives now underway. Over the last 30 years, King Research and more recently the University of Tennessee, School of Information Sciences, have conducted over 100 studies on the use of scientific scholarly communication and user behavior. These studies indicate trends and patterns that should be taken into consideration in the push towards digital publishing and implementing digital libraries.

Griffiths asks the panel for comment on the following observation:

During the opening session Bonnie Carroll quoted a survey that stated "one-third of those surveyed know what the information super highway is, and two-thirds think it is a good idea". From this, she concludes that user surveys are not what we should be looking at; instead, we should be looking at user expectations.

\footnotetext{
*In cooperation with The American Society for Information Science.
} 
Tenopir points out that Bonnie Lawlor in an earlier session commented that the user patterns and expectations used to shape future products should be those of the next generation, individuals who are now 18 or less. Tenopir says that children's information seeking behavior is a very hot area for study at the moment, with the most interesting work being done at the middle school age, when children first start their information gathering habits and specifically their interaction with the Web. She adds that there are real lessons to be learned from observing behavior and extrapolating the effect of change. Observations of the younger generation and identification of how their patterns differ from "older folk" can be used as an indicator of the need for different products or marketing in the future.

King offers some examples from survey results: a scientist, on average, reads one article from about 18 journals. The library supplies two-thirds of the materials a scientist reads, and the remainder is equally divided between personal subscriptions, journals shared by colleagues, and contacts directly with authors through preprints and reprints. The point is that, over the years, there has been a trend away from personal subscriptions to those supplied by the library. Scientists still read as much as they did 20 years ago, but where they get the information has changed. The reasons for change (economics, distance from the library, convenience) are likely to be influential in making decisions about using or subscribing to electronic journals as well.

Griffiths then asks:

"Given different information seeking patterns, can end users be spoken of as one category? How does one design information products that will be used by a wide range of people?"

Tenopir comments that they (she and King) tend to gather information in two areas of traits for research. They look at generalized traits through situational factors such as where people work, their job and level they are at within the organization, age, convenience, or level of motivation. Situational factors are often analogous to markets. Inherent factors are more personal and unique and do not change too much over time. They involve things such as cognitive style, affective behavior or sensory motor skills. These factors are reflected in the large number of personal portals that are appearing where people can design individual interfaces to meet their specific preferences.

King observes that part of the power of user surveys is to look at niche markets and see how users are different. For example, researchers in universities tend to progress along a line dictated by their own interest but, in industry, projects are dictated to researchers, and they may be triggered by things such as a change in market conditions, in a product line, or the whim of management. The different perspective on research has a dramatic effect on information seeking and reading patterns. Large collaborative research efforts are quite different from the smaller, more specialized area where contact with other scientists working on the same topic is limited. King also points out that they have found that most reading of life science and physical science articles is done outside of universities and outside the circle of authors who prepare the articles. Social scientists use libraries quite differently than scientists, and physical scientists use libraries differently than life scientists.

Question from the audience:

Since the users have so many choices now that have not been available in the past, how can we use past behavior to predict future use?

Tenopir points out that people are incorporators; as new formats become available, people incorporate them into their needs. However, as a generalization, younger people do not view print as an "authoritative format", and they tend to turn to the Web first as their first, best source. Information providers have to think beyond print, and electronic linkages will be important. King notes that there are three kinds of 
electronic journals: electronic only journals that are replicates of the traditional paper product; paper and electronic in parallel both of which are familiar to us; and those carrying the value-added process which will transform the way journals are created and used.

Question from Dick Kaser:

Over the time that King Research has been doing surveys, have there been discernable shifts in user patterns or have scientists kept doing the same thing?

King says the answer is "both". Browsing is important but mainly for current materials. Older material is obtained through libraries, but automated searching has become important and currently about $15 \%$ of the scholarly materials read are obtained in electronic form. The intermediary role is becoming more important especially in non-university settings.

Question from William Bug:

What about a researcher's use of structured vocabularies such as MEDLINE to locate materials?

King responds that searches requiring knowledge of specialized vocabularies are most frequently turned over to an intermediary to complete because they are complex. Researchers are quite skilled at starting the search and finding materials that are interesting to them. However, they usually stop at this point.

Question from Karen Hunter:

Have the studies shown a difference between asking a subject "What they would do if ..." versus giving them a prototype and observing how they use the prototype.

Tenopir notes that studies for years have shown that when you ask subjects in an information environment for their satisfaction level it is always higher than it appears in an experimental setting. People always seem to do better with concrete examples in context to which they can react. Griffiths observes that it is easier to recognize something when it is displayed to you than to recall it from memory, and there are probably parallels in this observation to using prototypes and thinking about what a prototype can do for you.

Griffiths moves to the issue of readership:

It has been stated in the literature that there are between 5 to 29 readings per article, and fewer than $1 \%$ of all the articles that have been written are read, so is the scientific journal even worth saving?

King responds that these figures were investigated by NSF which concluded that they could not possibly be true. In truth, the amount of reading per scientist has increased a little: within universities it is about 190 readings per scientist, outside the university it is about 110 readings per scientist. If you look at the number of articles distributed, 1 out of 10 is actually read, and a 10\% readership can be considered pretty good in the context of publishing.

Tenopir comments on some of the findings of the value studies that King, Griffiths, and she have done where they noted that the scientists who are higher readers of journal literature tend to be higher achievers and more successful. Journals are the most important source of information, and the high reader scientists are more productive, give more presentations, publish more, and submit more proposals. Scientists in industry publish less than scientists in university settings, but scientists in both settings find reading journals invaluable. 
King observes that the scientific literature doubles every 15 to 17 years. This means that, by the time scientists graduate from college, they will have been exposed to only one-sixth of the material they will have to master in their life time so they have to keep up or risk being left behind.

In response to a question from William Bug regarding how people locate information, King observes differences in information gathering habits among various scientific disciplines but as a generalization noted that reading may only account for $10-15 \%$ of a scientist's time, yet that scientist spends $50-65 \%$ of his/her time communicating. However, the time spent reading turns out to have more value in terms of its contribution to research and teaching.

David Russon asks if, given the massive growth in research and numbers of scientists as contrasted to the fact that scientists appear to be reading approximately the same number of articles as they did 30 years ago, we have made any difference? King comments that the output of scientists has remained remarkable as well, with some notable changes: the size of the typical articles has increased, and the number of published pages per scientist has increased due to multiple authorship. However, there is amazing stability to the publishing system.

Griffiths closes the session by noting some of the important issues and changes facing us as digital publishing becomes a reality: the issues of price, archiving, and assuring that the materials that scientists access and publish will be available in the future. King observes that traditional publishing is an expensive process, and typically it takes 5 to 6 years for a commercial journal to make a profit and recoup the start-up costs. The problem is that most journals only have between 500 and 1,000 subscribers and, to just recover costs, publishers have to charge between $\$ 700$ and $\$ 800$ per subscription. The fixed costs are such that you do not begin to reach a critical mass until you get to 2,500 to 5,000 subscriptions, and anything above that will cost more. Tenopir adds that if universities and legislatures continue to subsidize publishing we will see a revolution in publishing. 